\title{
S100A4 Protein in Inflammatory Bowel Disease: Results of a Single Centre Prospective Study
}

\author{
Paula Morávková ${ }^{1, *}$, Darina Kohoutová ${ }^{1}$, Jaroslava Vávrová2, Jan Bureš ${ }^{1}$
}

\begin{abstract}
Introduction: The aim of our study was to assess association of serum S100A4 protein with ulcerative colitis (UC) and Crohn's disease (CD). Methods: Study included 118 subjects: 93 patients with CD, 16 with UC and 9 controls. In CD group, 20/93 patients had B1 phenotype, 19/93 B2, 20/93 B3 and 34/93 B2 + B3. L1 involvement was present in 15/93, L2 in 14/93 and L3 in 64/93 patients. Serum S100A4 concentration was investigated in peripheral venous blood samples by means of ELISA.

Results: Serum S100A4 was significantly higher in UC (158.6 $\pm 56.2 \mathrm{ng} / \mathrm{mL}), \mathrm{p}=0.019$ and in CD $(154.4 \pm 52.1 \mathrm{ng} / \mathrm{mL}), \mathrm{p}=0.007 \mathrm{compared}$ to controls $(104.8 \pm 40.5 \mathrm{ng} / \mathrm{mL})$. No difference in S100A4 was revealed between UC and CD, $p>0.05$. Serum S100A4 in each $\mathrm{CD}$ subgroup (according to behaviour) was significantly higher compared to controls, $\mathrm{p}<0.05$. Serum S100A4 was significantly higher in $\mathrm{L} 2(144.6 \pm 44.2 \mathrm{ng} / \mathrm{mL}), \mathrm{p}=0.041$ and in $\mathrm{L} 3(163.0 \pm 52.8 \mathrm{ng} / \mathrm{mL}), \mathrm{p}=0.002$ compared to controls and in $\mathrm{L} 3$ compared to $\mathrm{L} 1(126.9 \pm 47.6 \mathrm{ng} / \mathrm{mL}), \mathrm{p}=0.017$.

Conclusion: Association of serum S100A4 protein with UC and CD was confirmed. In CD, disease behaviour did not influence serum concentration of S100A4 protein. In CD, higher levels of serum S100A4 were observed in patients with ileo-colonic and colonic involvement compared to those with isolated small bowel involvement.
\end{abstract}

\section{KEYWORDS}

S100A4 protein; inflammatory bowel disease; ulcerative colitis; Crohn's disease

\section{AUTHOR AFFILIATIONS}

${ }^{1}$ Charles University, Faculty of Medicine in Hradec Králové, University Hospital Hradec Králové, 2nd Department of Internal Medicine Gastroenterology, Hradec Králové, Czech Republic

${ }^{2}$ Charles University, Faculty of Medicine in Hradec Králové, University Hospital Hradec Králové, Institute of Clinical Biochemistry and Diagnostics, Hradec Králové, Czech Republic

* Corresponding author: Charles University, Faculty of Medicine in Hradec Králové, University Hospital Hradec Králové, 2nd Department of Internal Medicine - Gastroenterology, Sokolská 581, Hradec Králové, 50005 Czech Republic; e-mail: paula.moravkova@fnhk.cz

Received: 19 September 2017

Accepted: 21 October 2017

Published online: 5 February 2018

Acta Medica (Hradec Králové) 2017; 60(3): 108-113

https://doi.org/10.14712/18059694.2018.2

(c) 2017 The Authors. This is an open-access article distributed under the terms of the Creative Commons Attribution License (http://creativecommons.org/licenses/by/4.0), which permits unrestricted use, distribution, and reproduction in any medium, provided the original author and source are credited. 


\section{INTRODUCTION}

Inflammatory bowel disease (IBD), ulcerative colitis (UC) and Crohn's disease (CD) have become a global disease. Molodecky et al. reported in their recent study, that incidence and prevalence of IBD have been increasing worldwide. The highest prevalence of IBD has been documented in Europe and Canada (1).

Despite all the progress in contemporary diagnostics in medicine, there is no serum marker, which would be specific for IBD. Serum markers of inflammation - decreased thrombocyte volume and/or elevated thrombocyte count, white blood cell count, erythrocyte sedimentation rate and C-reactive protein - help to assess activity of IBD, mainly (2-7). Whichever antibody or combination of antibodies associated with IBD, including serum ASCA (anti-Sacharomyces cerevisiae antibodies), ABBA (anti-brush border antibodies), anti-I2 (antibodies to DNA fragments of Pseudomonas fluorescens), Anti-CBirl (antibodies to CBirl flagellin), anti-GP2 (antibodies to glycoprotein 2), anti-OmpC (anti-outer membrane protein $\mathrm{C}$ antibodies), pANCA (perinuclear anti-neutrophil cytoplasmic antibody), different levels of serum IgG1 and IgG2, ALCA (anti-laminaribioside carbohydrate antibodies), ACCA (anti-chitobioside carbohydrate antibodies) are present (8-15), their role to establish the definitive diagnosis of IBD/UC/CD is still supportive only.

The family of S100 proteins represents a total of at least 25 small calcium binding proteins. S100 proteins have a broad range of functions - they play an important role in the regulation of cell proliferation, differentiation, apoptosis, energy metabolism, cellular signalling, and calcium homeostasis (16). Involvement of S100 proteins in the pathogenesis of IBD has been clearly documented and the role of individual S100 proteins as biomarkers for CD and UC has been validated in multiple studies (17-23).

Calprotectin, a heterocomplex of S100A8/9 proteins, plays an important role in the regulation of different inflammatory processes and nowadays, faecal calprotectin is used for assessment of IBD activity on routine basis $(17,24)$.

S100A4 (metastatin-1, calvasculin) is localized in the nucleus, cytoplasm, and extracellular space. It is strongly associated with metastatic tumour progression (25).

Boye et al. emphasized that the nuclear expression (not the cytoplasmic one) of S100A4 is a novel prognostic marker for colorectal cancer (26) and further studies showed that S100A4 is not a biomarker only, but mediates the metastatic process itself, too (27).

Recent research has revealed that the role of S100A4 is more complex, including profibrotic effect e.g. in the myocardium, liver and intestine (28-30). Significant upregulation of S100A4 was observed in certain chronic inflammatory conditions, especially in patients with rheumatoid arthritis. It was shown, that increased secretion of TNF- $\alpha$, IL- $1 \beta$ and IL- 6 was mediated by S100A4 (31). The studies have demonstrated, that Toll-like receptor 4 (TLR-4), which plays a significant role in IBD, was involved in these pro-inflammatory S100A4 mediated processes $(32,33)$.

Fibroblasts represent the key cell type in the pathogenesis of fibrostenosing/stricturing CD. Cunningham et al. investigated S100A4 in ex-vivo culture of resected ileum in patients suffering from fibrostenosing $C D$. The explant culture of tissue originating from the stricture showed a significant overexpression of S100A4 (30).

We are fully aware, that faecal biomarkers, including calprotectin and S100A12, might have advantage over the serum biomarkers for their anticipated higher sensitivity (being produced by the inflamed mucosa into the intestinal lumen) and higher specificity (as serum biomarkers can be elevated due to non-gastrointestinal disorders) (17). Nevertheless, not a very rare preference of serum sampling to the faecal one by patients with IBD provoked us to investigate S100A4 protein in the serum.

To our best knowledge, there are no studies on S100A4 in different clinical IBD phenotypes in the literature.

The aim of our prospective study was to investigate serum S100A4 protein in patients with IBD and to determine possible association of increased serum S100A4 with complicated forms of CD.

\section{METHODS}

\section{SUBJECTS}

A total of 118 subjects were enrolled in the prospective study between 2009 and 2016: 93 patients with CD (44 men, 49 women, aged 22-79, mean $44 \pm 14$ ), 16 patients with UC ( 8 men, 8 women, aged 20-74, mean $39 \pm 15$ ) and 9 healthy controls ( 2 men, 7 women, aged 23-74, mean $52 \pm 17)$. Control group consisted of individuals with normal findings on colonoscopy, who had negative history of IBD and/or colorectal neoplasia. A recent change in bowel habit and symptoms compatible with irritable bowel syndrome were the indications for colonoscopy in that individuals. No patient in control group had any serious comorbidities in relation to the serum S100A4 protein (including rheumatic disorders).

CD group was divided according to the Montreal classification (34) and descriptive statistics is provided in Table 1.

The duration of UC was 3-18 years, mean $10 \pm 4$, the duration of CD was $1-39$ years, mean $15 \pm 9$. At the time of sampling, three patients with CD were without any treatment, 46 patients were on 5 -aminosalicylates (5-ASA) and 44 were treated with immunosuppressive therapy (corticosteroids, azathioprine, anti-TNF, cyclosporine). A total of $18 \%$ (17/93) were treated with anti-TNF agents, $4 / 17$ with adalimumab and $13 / 17$ with infliximab. A total of six CD patients were treated with antibiotics (ciprofloxacin and/or metronidazole) including one patient in group with 5-ASA and five CD patients with concomitant immunosuppressive therapy.

Within the UC group, all of the enrolled patients had 5-ASA; 3 patients were also treated with azathioprine. No patient from UC group received anti-TNF therapy.

\section{SERUM CONCENTRATION OF SIOOA4 PROTEIN:}

\section{SAMPLE COLLECTION AND MEASUREMENT}

Venous blood samples (total amount of $6 \mathrm{~mL}$ ) were obtained before a standard colonoscopy at the Endoscopy 
Tab. 1: The main characteristics of CD group.

\begin{tabular}{|l|l|l|l|l|}
\hline Behaviour & Subjects & Men/Women & Age & \multicolumn{2}{l|}{} \\
\cline { 5 - 5 } & Number, (\%) & & Range & Mean \\
\hline B1 & $20 / 93(22 \%)$ & $4 / 16$ & $22-64$ & $40 \pm 14$ \\
\hline B2 & $19 / 93(20 \%)$ & $11 / 8$ & $23-79$ & $48 \pm 15$ \\
\hline B3 & $20 / 93(21 \%)$ & $13 / 7$ & $24-59$ & $39 \pm 12$ \\
\hline B2 + B3 & $34 / 93(37 \%)$ & $16 / 18$ & $24-78$ & $47 \pm 14$ \\
\hline perianal & $27 / 93(29 \%)$ & $13 / 14$ & $24-69$ & $43 \pm 14$ \\
\hline Location & & & & \\
\hline L1 & $15 / 93(16 \%)$ & $9 / 6$ & $22-63$ & $41 \pm 13$ \\
\hline L2 & $14 / 93(15 \%)$ & $4 / 10$ & $22-64$ & $45 \pm 12$ \\
\hline L3 & $64 / 93(69 \%)$ & $31 / 33$ & $22-79$ & $44 \pm 15$ \\
\hline
\end{tabular}

Unit, 2nd Department of Internal Medicine-Gastroenterology. Samples were transferred immediately to the Institute of Clinical Biochemistry and Diagnostics at University Hospital Hradec Králové. Blood centrifugation followed and sera had been stored at $-80^{\circ} \mathrm{C}$ until the investigation was performed in December 2016. Serum concentration of S100A4 protein was investigated by means of Human Protein S100-A4 ELISA kit, the quantitative sandwich enzyme immunoassay technique (purchased from MyBio Source, San Diego, California, USA).

\section{ETHICAL ISSUES}

All subjects included in the study were given the necessary information and provided informed consent via a signed form. The project was approved by the Joint Ethical Committee (Charles University, Faculty of Medicine in Hradec Králové, University Hospital Hradec Králové). For all obtained data, all personal identification information was removed in compliance with the Czech laws for protection of confidentiality.

\section{STATISTICAL ANALYSIS}

Obtained data were tested statistically by means of descriptive statistic and non-paired t-test (normal distribution of data was confirmed) using STATISTICA software, version 13, 2013, Tulsa, OK, USA.

\section{RESULTS}

Serum S100A4 values were significantly higher in UC compared to controls, $\mathrm{p}=0.019$. Serum S100A4 were significantly higher in CD compared to controls, $p=0.007$. No difference in S100A4 serum levels was revealed between UC and CD group, $\mathrm{p}=0.771$. See Graph 1 .

In CD group, serum S100A4 was significantly higher in patients with all CD phenotypes compared to controls, $\mathrm{p}<0.05$. No difference in S100A4 was documented between particular subgroups of CD (divided according to behaviour of CD), $p>0.05$. See Graph 2.

According to disease localisation in CD group, a statistically significant difference in S100A4 was revealed

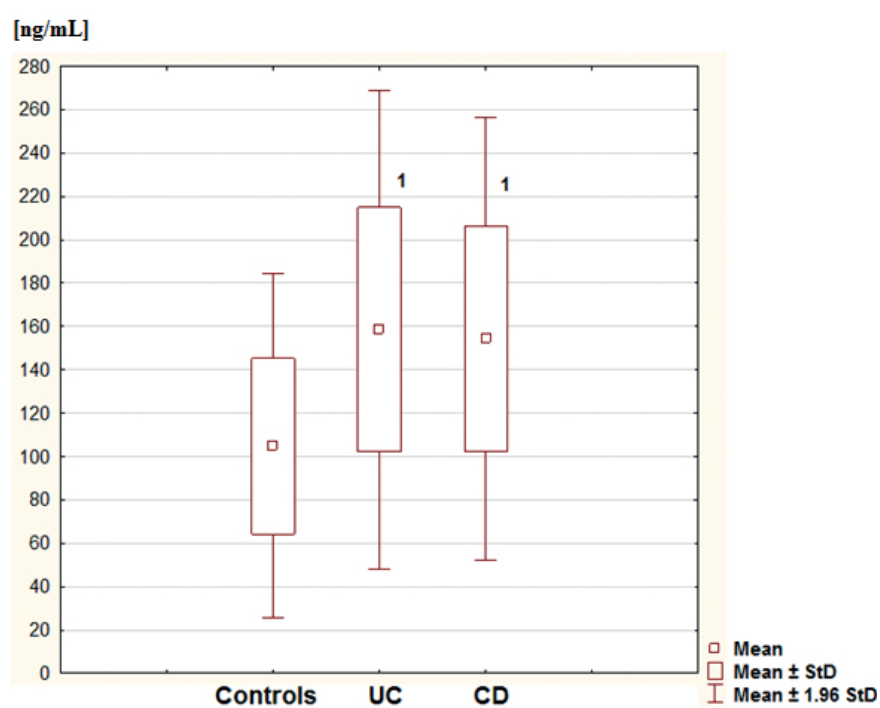

Graph 1: Comparison of serum concentration of S100A4 protein in controls, UC and CD patients.

1: significant difference compared to controls, $p<0.05$.

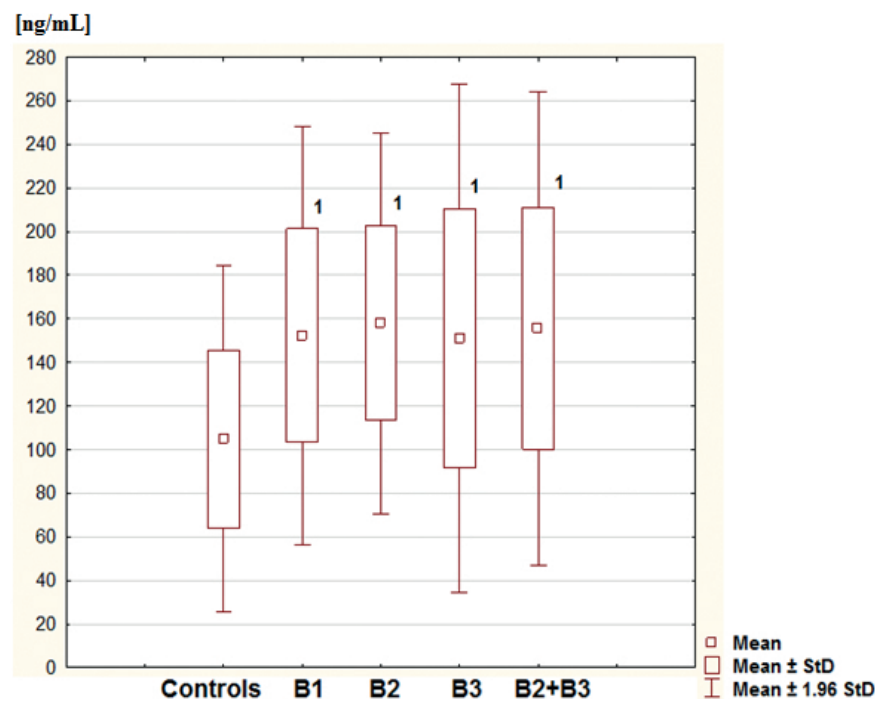

Graph 2: Comparison of serum concentrations of S100A4 protein in $\mathrm{CD}$ subgroups (divided according to the disease behaviour).

$B 1=$ nonstricturing-nonpenetrating, $B 2$ = stricturing,

$B 3=$ penetrating, $B 2+B 3=$ stricturing and penetrating form of $C D$. 1: significant difference compared to controls, $p<0.05$. 


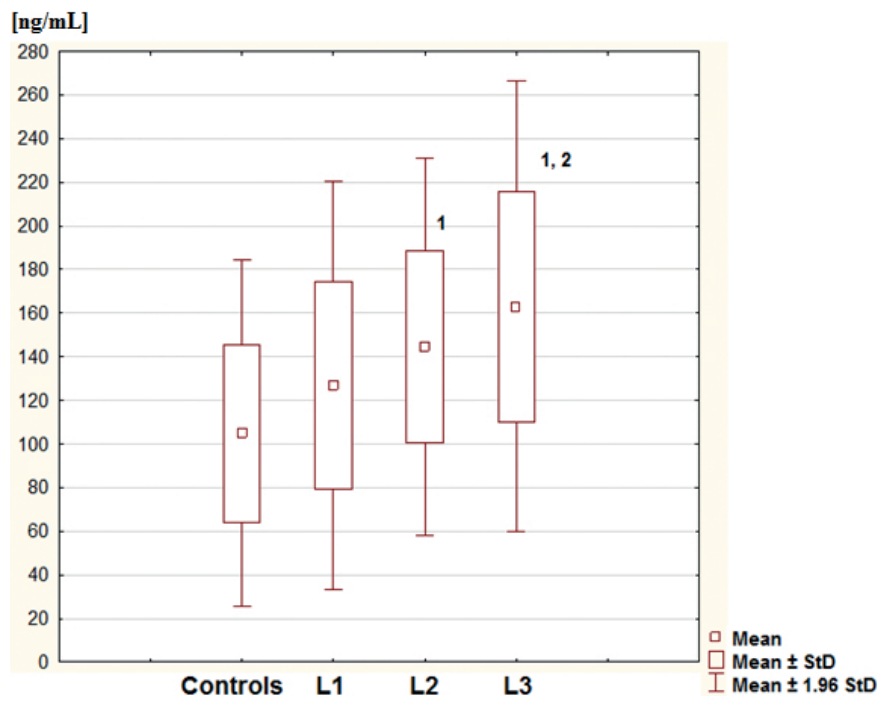

Graph 3: Comparison of serum S100A4 protein in controls and CD subgroups (divided according to the disease localization). $\mathrm{L} 1=$ isolated small bowel involvement, $\mathrm{L} 2 \mathrm{=}$ isolated colonic involvement, $\mathrm{L} 3$ = ileo-colonic involvement.

1: significant difference compared to controls, $p<0.05$.

2 : significant difference compared to $L 1, p<0.05$.

between L2 subgroup compared to controls, $p=0.041$ and between L3 compared to controls, $p=0.002$. Significant difference in S100A4 was revealed between L1 and L3, $\mathrm{p}=0.017$. See Graph 3 .

CD patients with $(27 / 93 ; 29 \%)$ and without perianal involvement $(66 / 93 ; 71 \%)$ had significantly higher serum S100A4 (mean $163.1 \pm 60.6 \mathrm{ng} / \mathrm{mL}$; mean $150.8 \pm 48.3 \mathrm{ng} / \mathrm{mL}$, respectively) compared to controls, $\mathrm{p}=0.002$. The difference in serum S100A4 between CD with and without perianal involvement was not statistically significant, $\mathrm{p}>0.05$.

All CD patients, regardless if treated with anti-TNF agents, had significantly higher serum concentration of S100A4 compared to controls: CD group with anti-TNF: mean $154.7 \pm 65.5 \mathrm{ng} / \mathrm{mL}, \mathrm{p}=0.049$; $\mathrm{CD}$ group without anti-TNF: mean $154.3 \pm 49.2 \mathrm{ng} / \mathrm{mL}, \mathrm{p}=0.005$. There was no significant difference in serum S100A4 between CD patients with and without anti-TNF medication, $\mathrm{p}>0.05$.

\section{DISCUSSION}

In our study, serum S100A4 levels were significantly elevated in patients with ulcerative colitis and in patients with Crohn's disease compared to controls. We are convinced, that S100A4 is not a biomarker of IBD only, but it also plays a crucial role in the development of inflammatory process itself, presumably through the activation of TLR receptors and NF- $\kappa \beta$ signalling pathway, too. In patients with rheumatoid arthritis, high levels of S100A4 were associated with a poor clinical response to infliximab and a high rate of anti-infliximab antibodies (35). Based on these data, similar situation could be expected in IBD patients and therefore a study evaluating S100A4 before the patients are started on anti-TNF therapy is being planned in our setting. No difference in serum S100A4 was confirmed between $C D$ patients with and without anti-TNF in our study, however no firm conclusions can be drawn from this, as no one has studied the impact of anti-TNF therapy on serum S100A4 so far. S100A4 protein, known as calvasculin or metastatin-1 (16), was isolated by Ebralidze in 1989 and was considered to be involved in the metastatic tumour cell phenotype (36). A recent metaanalysis carried out by Liu et al. was in agreement: they reported that S100A4 over-expression correlates with tumour progression and poor prognosis of patients with colorectal carcinoma (37).

Recent studies have documented, that S100A4 does not play a role in metastatic cancer only, but it is also involved in inflammatory processes (38). Increased expression of calvasculin was documented in inflamed muscle tissue in patients with idiopathic inflammatory myopathies, where S100A4 may stimulate mononuclear cells to increase synthesis of pro-inflammatory cytokines (39). Significant upregulation of S100A4 was also observed in patients with rheumatoid arthritis: a study performed by Cerezo et al. documented that calvasculin induces inflammatory response (up-regulated production of TNF (tumour necrosis factor) $-\alpha$, IL (interleukin)- $1 \beta$ and IL- 6 ) of mononuclear cells via the TLR-4 (toll-like receptor) and by the activation of NF- $\kappa B$ signalling pathway (31). Aberrant TLR signalling is known to contribute to intestinal inflammatory processes in IBD and associated carcinoma $(32,33)$. NF- $k \beta$ signalling cascade has also been shown to be involved in the development of colitis associated carcinoma (40).

Cunningham et al. found increased expression of S100A4 in fibroblasts and immune cells in the resected ileum in patients with stricturing $C D$. They also reported that the over-expression of S100A4 was induced by TGF- $\beta 1$ (transforming growth factor) (30). Therefore we assumed, that patients with stricturing phenotype of $C D$ will have higher serum S100A4 compared to those with a non-stricturing $C D$ behaviour. Nevertheless, our data have shown that patients with all phenotypes of $C D$ had significantly elevated serum S100A4 compared to controls and no significant difference in serum S100A4 was observed between stricturing and non-stricturing $C D$ phenotypes. This might be explained by the fact, that over-expression of S100A4 in fibrotic processes is observed in tissue specific manner reflecting the local situation in the damaged tissue. We hypothesize therefore, that elevation of serum S100A4 protein (found in both, patients with UC and CD), mirrors rather inflammatory properties of calvasculin and its involvement in inflammatory processes in IBD.

Role of S100A4 in fibrotic processes has been investigated recently: Tamaki et al. studied effect of S100A4 on cardiac fibrosis and documented, that S100A4 knockout mice showed reduced interstitial fibrosis, decreased number of myofibroblasts, suppressed expressions of collagen and profibrotic cytokines in the left ventricle. The authors assume, that the S100A4 induces cardiac fibrosis through the modulation of p53 (28). Effect of S100A4 in the ischaemic myocardium seems to be different - protective and regenerative mainly: calvasculin decreased apoptosis of cardiac myocytes via the AKT signalling pathway (41) or via the ERK pathway (42).

We found the presence of highest S100A4 levels in patients with ileo-colonic and colonic forms of $C D$ very interesting. Based on the literature, there is no definitive 
explanation for this. Nevertheless, (1) reported activation of NF- $k \beta$ signalling cascade by S100A4 (31), (2) suggestion that the NF- $\kappa \beta$ signalling cascade may be the central mediator of gastrointestinal inflammation in IBD and malignancies (40), (3) known properties of metastatin - being a mediator of metastatic processes (27), (4) and known association of colorectal carcinoma with IBD (43) are compatible with our observation of higher levels of serum S100A4 in IBD patients with colonic involvement.

We are aware of the possible limits of our current study. On the basis of the available literature, where S100A4 was investigated either in the serum (51 studies; two of them in a relation to a gastroenterology disorder liver fibrosis and cirrhosis $(44,45))$ or in plasma samples (26 studies; two of them were accomplished in gastric and colorectal cancer $(46,47)$ ), we decided to investigate serum S100A4. All individuals enrolled into our study including all healthy controls and all IBD patients were investigated in the same manner. Therefore we assume, that our results are valuable and plausible despite we do not have any comparison between plasma and serum concentrations in our patients. Further, we did not investigate mRNA for S100A4 tissue expression (from the affected areas), therefore it was not possible to correlate it with the serum S100A4. The reasons why we did not investigate the tissue samples were two: a) middle part of the small intestine may not be easily accessible for a routine endoscopy, b) resected specimens might not reflect situation in the whole intestine.

We hypothesize, that serum S100A4 can help to distinguish between IBD and non-IBD population and it possibly might serve as a phenotype marker of IBD (colonic involvement), however further studies are needed to follow in the near future.

\section{CONCLUSIONS}

Association of serum S100A4 with inflammatory bowel disease was confirmed.

No difference in serum S100A4 was observed between particular phenotypes of Crohn's disease (CD) including stricturing and non-stricturing forms of $\mathrm{CD}$.

In $C D$, serum S100A4 was higher in patients with colonic and ileo-colonic involvement compared to patients with isolated small bowel involvement.

\section{ACKNOWLEDGEMENTS}

The study was supported by the Project PROGRES from Charles University (Q40-15) and by Specific University Research Programme (SVV 260396), Faculty of Medicine in Hradec Králové.

\section{REFERENCES}

1. Molodecky NA, Soon IS, Rabi DM, et al. Increasing incidence and prevalence of the inflammatory bowel diseases with time, based on systematic review. Gastroenterology 2012; 142(1): 46-54.

2. Bures J, Horacek J, Pecka M, et al. Thrombocytes as an indicator of activity in Crohn's disease treated with total parenteral and/or enteral nutrition. Vnitr Lek 1994; 40: 84-8. (Article in Czech).
3. Douda T, Bures J, Rejchrt S, Kopacova M, Pecka M, Maly J. Mean platelet volume in Crohn's disease patients. Cas Lek Cesk 2006; 145: 870-3. (Article in Czech).

4. Kohoutova D, Pecka M, Cihak M, Cyrany J, Maly J, Bures J. Prevalence of hypercoagulable disorders in inflammatory bowel disease. Scand J Gastroenterol 2014; 49(3): 287-94.

5. Vermeire S, Van Assche G, Rutgeerts P. C-reactive protein as a marker for inflammatory bowel disease. Inflamm Bowel Dis 2004; 10: 661-5.

6. Fagan EA, Dyck RF, Maton PN, Hodgson HJ, Chadwick VS, Petrie A, Pepys MB. Serum levels of C-reactive protein in Crohn's disease and ulcerative colitis. Eur J Clin Invest 1982; 12: 351-9.

7. Chamouard P, Richert Z, Meyer N, Rahmi G, Baumann R. Diagnostic value of C-reactive protein for predicting activity level of Crohn's disease. Clin Gastroenterol Hepatol 2006; 4: 882-7.

8. Xiong Y, Wang GZ, Zhou JQ, Xia BQ, Wang XY, Jiang B. Serum antibodies to microbial antigens for Crohn's disease progression: a meta-analysis. Eur J Gastroenterol Hepatol 2014; 26(7): 733-42.

9. Mow WS, Vasiliauskas EA, Lin YC, et al. Association of antibody responses to microbial antigens and complications of small bowel Crohn's disease. Gastroenterology 2004; 126(2): 414-424.

10. Pintér M, Pintérová KM, Drahosová M, et al. Cas Lek Cesk 2007; 146(11): 863-7. (Article in Czech).

11. Targan SR, Landers CJ, Yang H, et al. Antibodies to CBir1 flagellin define a unique response that is associated independently with complicated Crohn's disease. Gastroenterology 2005; 128(7): 2020-2028.

12. Kohoutova D, Drahosova M, Moravkova P, Rejchrt S, Bures J. Anti-Outer membrane protein $C$ and anti-glycoprotein 2 antibodies in inflammatory bowel disease and their association with complicated forms of Crohn's disease. BMC Gastroenterol 2014; 14: 190.

13. Rump JA, Schölmerich J, Gross V, et al. A new type of perinuclear anti-neutrophil cytoplasmic antibody (p-ANCA) in active ulcerative colitis but not in Crohn's disease. Immunobiology 1990; 181(4-5): 406-413.

14. Muller-Ladner U, Gross V, Andus T, et al. Distinct patterns of immunoglobulin classes and IgG subclasses of autoantibodies in patients with inflammatory bowel disease. Eur J Gastroenterol Hepatol 1996; 8: 579-584.

15. Rejchrt S, Drahosová M, Kopácová $M$, et al. Antilaminaribioside and antichitobioside antibodies in inflammatory bowel disease. Folia Microbiol (Praha) 2008; 53(4): 373-6.

16. Moravkova P, Kohoutova D, Rejchrt S, Cyrany J, Bures J. Role of S100 Proteins in Colorectal Carcinogenesis. Gastroenterol Res Pract 2016; 2016: 2632703.

17. Lopez RN, Leach ST, Lemberg DA, Duvoisin G, Gearry RB, Day AS. Faecal Biomarkers in Inflammatory Bowel Disease. J Gastroenterol Hepatol 2016. doi: 10.1111/jgh.13611. (Epub ahead of print).

18. Marenholz I, Heizmann CW, Fritz G. S100 proteins in mouse and man: from evolution to function and pathology (including an update of the nomenclature). Biochem Biophys Res Commun 2004; 322(4): 1111-22.

19. Ryckman C, Vandal K, Rouleau P, Talbot M, Tessier PA. Proinflammatory activities of S100: proteins S100A8, S100A9, and S100A8/ A9 induce neutrophil chemotaxis and adhesion. J Immunol 2003; 170(6): 3233-42.

20. Hofmann MA, Drury S, Fu C, et al. RAGE mediates a novel proinflammatory axis: a central cell surface receptor for S100/calgranulin polypeptides. Cell 1999; 97(7): 889-901.

21. Wright EK, Kamm MA, De Cruz P, et al. Comparison of Fecal Inflammatory Markers in Crohn's Disease. Inflamm Bowel Dis 2016; 22(5): 1086-94

22. Cozijnsen MA, van Pieterson M, Samsom JN, Escher JC, de Ridder L. Top-down Infliximab Study in Kids with Crohn's disease (TISKids): an international multicentre randomised controlled trial. BMJ Open Gastroenterol 2016; 3(1): e000123.

23. Chatzikonstantinou M, Konstantopoulos P, Stergiopoulos S, et al. Calprotectin as a diagnostic tool for inflammatory bowel diseases. Biomed Rep 2016; 5(4): 403-407.

24. Korndörfer IP, Brueckner F, Skerra A. The crystal structure of the human (S100A8/S100A9)2 heterotetramer, calprotectin, illustrates how conformational changes of interacting alpha-helices can determine specific association of two EF-hand proteins. J Mol Biol 2007; 370(5): 887-98.

25. Schmidt-Hansen B, Ornås D, Grigorian $M$, et al. Extracellular S100A4(mts1) stimulates invasive growth of mouse endothelial cells and modulates MMP-13 matrix metalloproteinase activity. Oncogene 2004; 23(32): 5487-95.

26. Boye K, Nesland JM, Sandstad B, Mælandsmo GM, Flatmark K. Nuclear S100A4 is a novel prognostic marker in colorectal cancer. Eur J Cancer 2010; 46(16): 2919-25. 
27. Sack U, Stein U. Want up your mind - intervention strategies for S100A4-induced metastasis in colon cancer. Gen Physiol Biophys 2009; 28: F55-64.

28. Tamaki Y, Iwanaga Y, Niizuma S, et al. Metastasis-associated protein, S100A4 mediates cardiac fibrosis potentially through the modulation of p53 in cardiac fibroblasts. J Mol Cell Cardiol 2013; 57: 72-81.

29. Louka ML, Ramzy MM. Involvement of fibroblast-specific protein 1 (S100A4) and matrix metalloproteinase-13 (MMP-13) in CCl4-induced reversible liver fibrosis. Gene 2016; 579(1): 29-33.

30. Cunningham MF, Docherty NG, Burke JP, O'Connell PR. S100A4 expression is increased in stricture fibroblasts from patients with fibrostenosing Crohn's disease and promotes intestinal fibroblast migration. Am J Physiol Gastrointest Liver Physiol 2010; 299(2): G457-66.

31. Cerezo LA, Remáková M, Tomčik M, et al. The metastasis-associated protein S100A4 promotes the inflammatory response of mononuclear cells via the TLR4 signalling pathway in rheumatoid arthritis. Rheumatology (Oxford) 2014; 53(8): 1520-6.

32. Fernandes P, MacSharry J, Darby T, et al. Differential expression of key regulators of Toll-like receptors in ulcerative colitis and Crohn's dis ease: a role for Tollip and peroxisome proliferator-activated receptor gamma? Clin Exp Immunol 2016; 183(3): 358-68.

33. Cario E. Toll-like receptors in inflammatory bowel diseases: a decade later. Inflamm Bowel Dis 2010; 16(9): 1583-97.

34. Silverberg MS, Satsangi J, Ahmad T, et al. Toward an integrated clinical, molecular and serological classification of inflammatory bowel disease: report of a Working Party of the 2005 Montreal World Congress of Gastroenterology. Can J Gastroenterol 2005; 19 Suppl A: 5A-36A.

35. Erlandsson MC, Forslind K, Andersson SE, Lund A, Bokarewa MI. Metastasin S100A4 is increased in proportion to radiographic damage in patients with RA. Rheumatology (Oxford) 2012; 51(5): 932-40.

36. Ebralidze A, Tulchinsky E, Grigorian M, et al. Isolation and characterization of a gene specifically expressed in different metastatic cells and whose deduced gene product has a high degree of homology to a Ca2+-binding protein family. Genes Dev 1989; 3(7): 1086-93.
37. Liu Y, Tang W, Wang J, et al. Clinicopathological and prognostic significance of S100A4 overexpression in colorectal cancer: a meta-analysis. Diagn Pathol 2013; 8: 181.

38. Grigorian M, Ambartsumian N, Lukanidin E. Metastasis-inducing S100A4 protein: implication in non-malignant human pathologies. Curr Mol Med 2008; 8(6): 492-6.

39. Cerezo LA, Kuncová K, Mann H, et al. The metastasis promoting protein S100A4 is increased in idiopathic inflammatory myopathies. Rheumatology (Oxford) 2011; 50(10): 1766-72.

40. Tambuwala MM. Natural Nuclear Factor Kappa Beta Inhibitors: Safe Therapeutic Options for Inflammatory Bowel Disease. Inflamm Bowel Dis 2016; 22(3): 719-23.

41. Doroudgar S, Quijada P, Konstandin M, et al. S100A4 protects the myocardium against ischemic stress. J Mol Cell Cardiol 2016; 100: 54-63.

42. Schneider M, Kostin S, Strøm CC, et al. S100A4 is upregulated in injured myocardium and promotes growth and survival of cardiac myocytes. Cardiovasc Res 2007; 75(1): 40-50.

43. Axelrad JE, Lichtiger S, Yajnik V. Inflammatory bowel disease and cancer: The role of inflammation, immunosuppression, and cancer treatment. World J Gastroenterol 2016; 22(20): 4794-801.

44. Yan LB, Zhang QB, Zhu X, He M, Tang H. Serum S100 calcium binding protein A4 improves the diagnostic accuracy of transient elastography for assessing liver fibrosis in hepatitis B. Clin Res Hepatol Gastroenterol 2017; S2210-7401(17): 30144-4.

45. Chen L, Li J, Zhang J, et al. S100A4 promotes liver fibrosis via activation of hepatic stellate cells. J Hepatol 2015; 62(1): 156-64.

46. Burock S, Herrmann P, Wendler I, Niederstrasser M, Wernecke KD, Stein U. Circulating Metastasis Associated in Colon Cancer 1 transcripts in gastric cancer patient plasma as diagnostic and prognostic biomarker. World J Gastroenterol 2015; 21(1): 333-41.

47. Stein U, Burock S, Herrmann P, Wendler I, et al. Diagnostic and prognostic value of metastasis inducer S100A4 transcripts in plasma of colon, rectal, and gastric cancer patients. J Mol Diagn 2011; 13(2): 189-98. 